\title{
ISOTOPE HEAT SOURCE FOR DYNAMIC POWER SYSTEMS
}

\author{
Alfred Schock
}

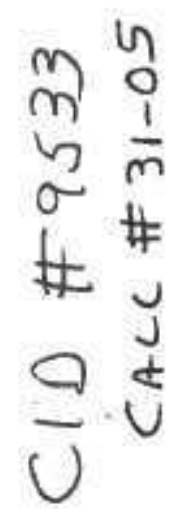

\author{
Fairchild Space and Electronics Company \\ Gernantown, Maryland 20767
}

Prepared for Presentation at the Eleventh Intersociety Energy Conversion Engineering Conference, September 1976 
ISOTOPE HEAT SOURCE FOR DYNAMIC POHER SYSTEMS

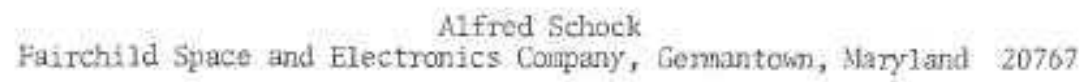

Abstroat

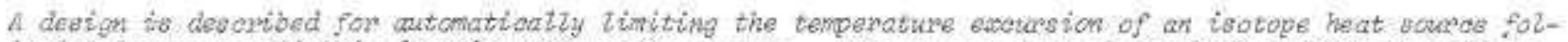

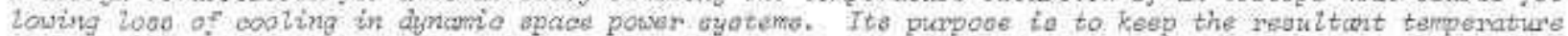
risc amall enough and brief enough to preyent juet capsule degradation: i.s., not nereity to avoid moltdown,

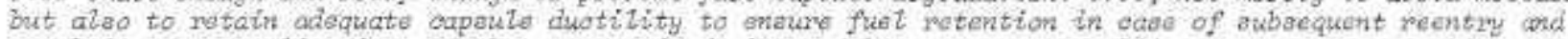
earth impact. Applieations of the andept in derigna of heat boures asembities for Broyton, iaskine, and Stirling ogote paser ayatema are illuatrated.

\section{INTRODUCIION}

The Nuclear Research and Applications Division of ERDA is developing a number of new, tsotope-fueled, electrical power systems in the $/ 2-t_{0}-2 \mathrm{kw}(e)$ range, for space and terrestrial applications. Included are both static (thermoelectric) and dymanic

(Brayton, Rankine, Stirling) systems. Each system requires one or a fer hest source assemblies in the low-kw(t) range, with built-in provisions for ensuring fuel retention under all credible accident conditions. This problem has already been solved in the isotope heat sources used in thernoelectric pawer systems in previous space flights.

The advent of high-efficiency dynanic power conversion systens, however, raises a new problen: disposal of the isotope decay heat aftor the dymamic systen stops operating. Plutonium-238, the radioisotope used in space, has a half-1ife of about 87 years. Space power systems are designed for typical lifetines of 5-to-10 vears. Thus, most of the fuel is still active at the time of anticipated power system failure,

This is no particular problem in the case of the themoelectrit generators, where most of the heat (over 908) is lost by conduction through the thermoelements and instilation, and only a small fraction is lost by Peitier cooling. Under those conditions, Ioss of Peltier ccoling causes only a podest increase in heat source temperature.

In a woll-designed dynanic power system, only a small fraction ( 108 ) of the heat is lost through the insulation during nomal operation. Most of the heat is renoved via the dymanic conversion systen. Failure of that systen (e.g., loss of working fluid) will cause the heat source temperature to rise slow: $1 y$ (i.e., at an initial rate of about $10^{\circ} \mathrm{g} / \mathrm{min}$ ). This process will continue until the heat source roaches a temperature where all of the isotope decay heat can be rejected through the therral insulation. In well-insulated systemis the resultant heat source temperature would exceed the melting point of the fuel capsules. Clearly, an arramgement is needed which will automatically reduce the thermal insulation effectiveness before the heat source can rise to a temperature where excessiva capsule degradation occurs. Such degradation could lead to fuel release during subsequent atmospheric reentry or earth impact.

The required emergency cooling system (ECS) must activate automatically when reeded, and be as close to fail-safe as possible. One proposed ECS design, urder current developinent for a Brayton power system [1], attenpts to achieve those goals by using nickel foils for the thermal insulation. When the coolant flow stops, the heat source rises in temerature until all or most of the rickel foils nelt and/or evaporate, which greatly reduces the offectiveness of the thermal insulation. Activation of such a system is certainly fail-safe, and analysis shows that it will prevent melt-dow of the fuel capsules and subsequent fuel dispersion during stuospherie reentry.

The fuel capsules, however, must also perform a second function, namely containnent of respirable fuel particles during and after earth impact. This second function requires rot only that the iridium capsules not melt, but also that they retain their ductility, which is necessary for subsequent inpact survival. This is a much more severe reauirement, since tests indicate that grain growth may cause iridiun alloys to lose much of their ductility far below the meiting point of iridium or of the Ir-C eutectic.

A prelininary analysis of the melting-foil concept (which included the effects of radiation, conduction, foil meltdown and foil vaporization, but did not include the possible effects of sintering or selfwelding) indicated that the concept, while adecuate to prevent capsule meltdown, may not be adequate to prevent excessive ductility degradation. The analy. sis showed the $* 10$ hotirs of the temperature excursion elapse before the innemost nickel foil starts to melt, at which time the fuel capsule tenperatures exceed $3000^{\circ} \mathrm{F}$ (compared to their nomal $2400^{\circ} \mathrm{F}$ level) and are still rising. Retention of adequate ductility of current iridiun alloys subjected to such a temperature excursion has not been demonstratod, and secms questionable. It therefore appears desirable to provide the heat source assembly (HSA) with another ECS arrangement, to terminate the temperature excursion more quickly, and at much lower peak capsule temperatures.

The use of foils with lower melting points than rickel has been considered, but lower-melting metals tend to have higher vapor pressures, which would lead to excessive evaporation rates at normal operating teaperatures. The use of lower-melting, lowvapor-pressure eutectic mixtures has been proposed [2] , but these would be difficult to form into thin foils, and would require an extensive development and test progran to demonstrate their reliability. 
One pessible arrengetuent for avoiding the drawbacks of the melting-foil concept is to devise a system for autonatically removing all or part of the thermal insulation when the heat source exceeds a predetemined tomperature level. This insulation renoval can be spring activated, triggered by meltdown: of a fusible link which is theranlly coupled to the heat source. The springs themselves can be located in a Iow-temperature regian of the HSA.

One of the principal problems in devising a design to implenent the above insulation-removal concept relates to the question of how to provide adequate structural support for the radioisotope heat source, without incurring excessive heat loss by thermal conduction. The support structure aust be strong enough to withstand latuch vibrations, yet compliant enough to allow for thermal expansion. This will be illustrated with respect to an actanl heat source which has already flown as part of the Multi-flundredWatt (MTh) themoelectric generator.

The heat source contains twenty four 100 -watt spherical fuel elemerts, each with its onn fuel containment capsule and impact protection shell. Reentry protection for the heat source is provided by a cylindrical graphite shell with end caps. In the Mill generator the cylindrical heat source is supported solely by axial conpression from its two ends. An axial preload of $1200 \mathrm{lbs}$ is required to withstand launch loads. The conpressive supports pass out through the center of the end insulations, where they transmit the preload through compliant spiders to the generator housing. This speciflc support arrangement would be incompatible with the insulation-removal ECS concept discussed above, since the support structure must not obstruct the insulation which is to be renoved. A different support asrangement is therefore required.

For a cylindrical heat source, an ECS deston can be based on the rembval of either the side or the end insulation. Either arrangentent seems to be feasible. Removal of the side insulation-would be thermally more effective. However, as shown in Reference [3], removal of the two end insulators also gives adequate overtemperature protection. Analysis indicates that with both end insulators removed, the heat source surface equilibrates at $1076^{\circ} \mathrm{F}$ at its ends, and at $1640^{\circ} \mathrm{F}$ at its hottest point, near the mid-plane. These equilibrium values, as well as the transient temperatures experienced after BCS activation, are well below the nomal operating tenperatures of the Brayton system heat source. The endinsulation renoval scheme was the refore selected, because it pemnits a sonethat simpler solution of the structural support problem.

To have renovable end insulators, the support menbers cornecting the heat source to the HSA housing musi pass through the cylindrical side insulation. A possible arrangement for doing this is illustrated in Figure 1 .

At the center of the HSA, and occupying nost of its voluts, is the orlindrical heat source, which is essentially fdentical to that of the MW generator. Surrounding the cylfndrical heat source is a helical tube heat exchanger, in which the isotope decay heat is transferred to the Brayton system's inert gas working fluid. The helical heat exchanger is in tum surrounded by multifoil insulation, to minimize heat losses to the cool ( $200^{\circ} \mathrm{F}$ ) generator housing. The coolant inlet and outlet ports of the heat exchanger ponetrate through the side insulation and the HSA housing.

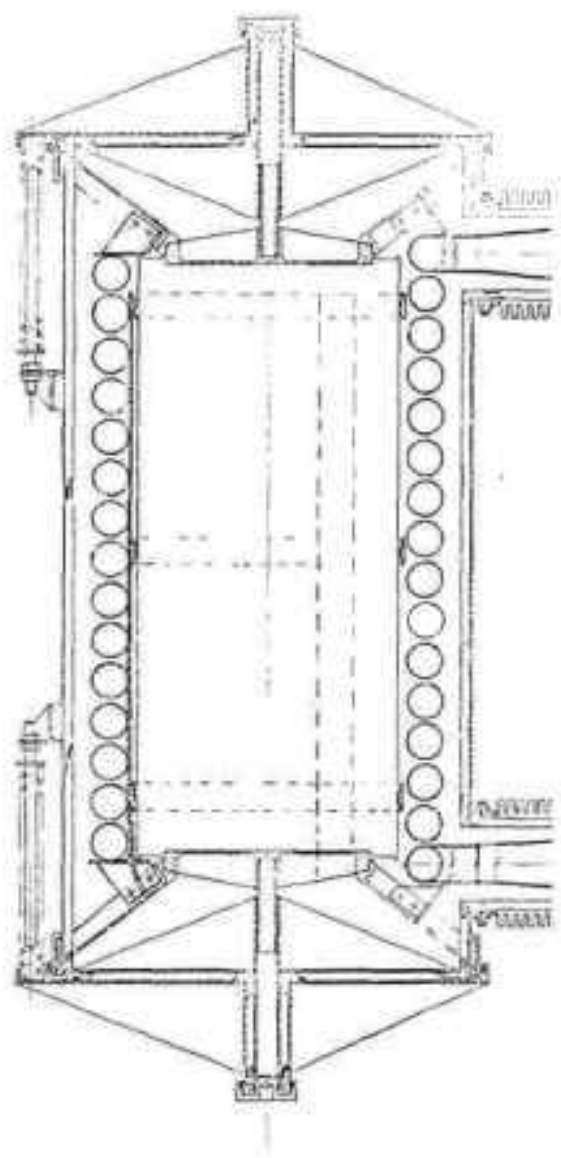

Figune 1. Inturtrative Beat Source Derign for Broyton-Cyale Power Bystem

The axial and lateral loads exerted by the heat source during launch are supported by three equispaced flat tabs at each end of the HSA. As shown in Figure 1, each support tab passes through a narrow axial slit at the end of the side insulition blanket. The inside end of each tab is comnected to an inner ring which supports the end of the heat source; and the outside end of each tab is connected to an cuter ring, which is mounted to the HSA housing.

The ring-tabs-ring structure at each HSA end is dimensioned to yield the desired degree of strength and conpliance, and the mounting to the HSA housing is adjusted to give the desired compressive preload. The support structure is stiff axially and radialiy (but not tangentially, since rotational forces are sma11). The portion of each support tab within the HSA's insulation blanket is itsclf insulated with multi-foil (not shown in Figure I), to lengthen the heat conduction path and reduce themal losses.

The end covers are sealed to the HSA housing by means of Viton O-rings. Viton has long-term realiability up to $392^{\circ} \mathrm{F}$. Before and during launch, the HSA may be filled with helium, to prevent excessive heat source temperatures even when the Brayton system is 
not operating. After launch, the seals are no longer needed, since the HSA is vented to space.

Each end cover has an integral multi-foil insulation blarket. A stepped nitre joint is used between the sides and end insulations. Each end cover assembly is acted on by three compressed springs trying to push it away from the HSA housing. The springs are outside the housing and thetefore cool, A stifferied retaining plate on the inside of each end cover insulation blanket assures removal of that insulation with its cover.

The spring force on each cover is resisted by a centrally located axial tube, which penetrates through the end insulation and connects that end cover assembly to the heat source. The tube's cross-sectional area is designed to give adequate creep strength to resist the tension produced by the six springs, and its length is chosen to yield adequate thermal resistance.

The portion of the axial tube inside the insulation package, adjacent to the heat source, contains a braze joint designed to melt at a predetermined tenperature. That temperature is chosen low enough to nininize the magnitude and duration of the coolantloss temperature excursion, but high enough to avoid the danger of inadvertent end cover deployment due to temperature fluctuations during normal operation. The braze joints at the two ends of the HSA may have different twelting points, to reflect the nomally present axial tenperature gradient of the heat source. The braze bond connects two coaxial tubes by means of a Lap joint, which is made long enough to reduce the shear stress sufficiently to avoid creep failure.

The insulation-renoval systen described above does not recessarily have to replace the previously nentioned foil-meltdown system. The two systems can be used in confunction, to supplenent each other. Such a combined ECS would protect the fuel capsules against loss of ductility, and still retain the extremely reliable foil meltown concept as backup protection against capsule melting.

Wille the above discussion his dealt primarily with the Brayton power system, the sane insulation-renoval emergency cooling concept can also be applied to other power sytems. Figure 2 illustrates a very similar HSA design for the Organic Rankine system, with the helical heat exchanger tube acting as the boiler for the Dowtherm working fluid. And Figure 3 illustrates the application of the same ECS principle to an IESA design for a Stirling-cycle power system, with the ASA in themal contact with the cyI inder head of the engine.

\section{REPERENCES}

1 Wein, D. 'Development of a Heat Source Assembly for an Isotope-Bratyon Space Power Conversion System", Proceedings of the 1975 Intersocioty Energy Conversion Engineering Conference,p.901.

2 Kling, H.P., "Composite Multi-Foil Insulation for Overheat Protection", Fairchild Industries, Gemantawn, Maryland, Report \& FSEC-NSG-217-75/54.

3 GE Report GESP-7103, "Final Report, Mini-Brayton Heat Source Asseinbly Design Study", NASA-CR121223, Lecenber 1973.

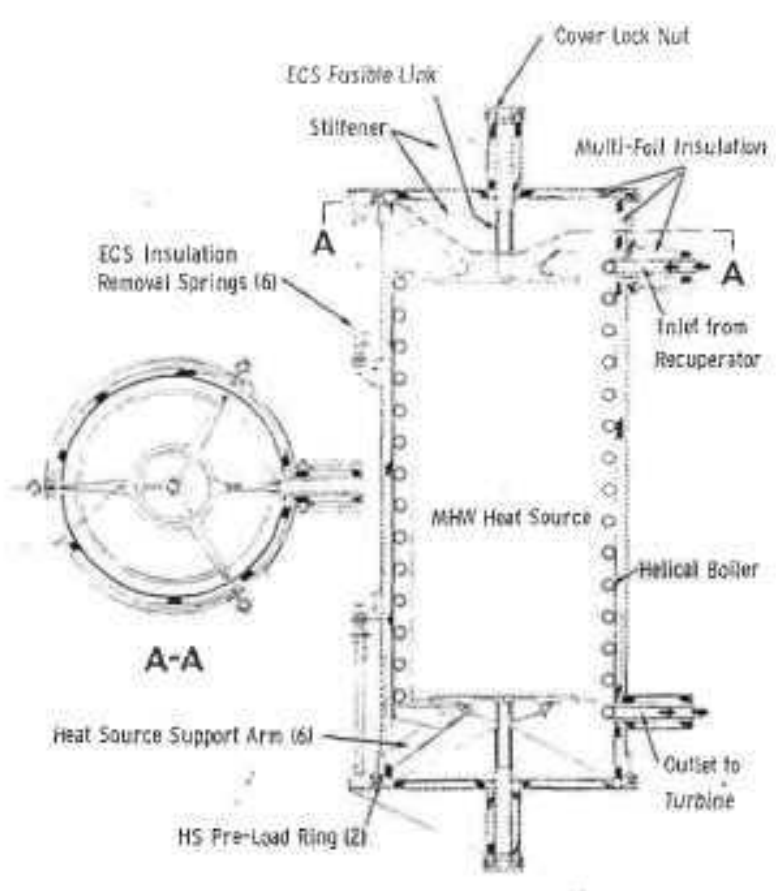

Figure 2. Itlustrative Heat sowes Deeign for Rionicine-Cyate Power Syatem

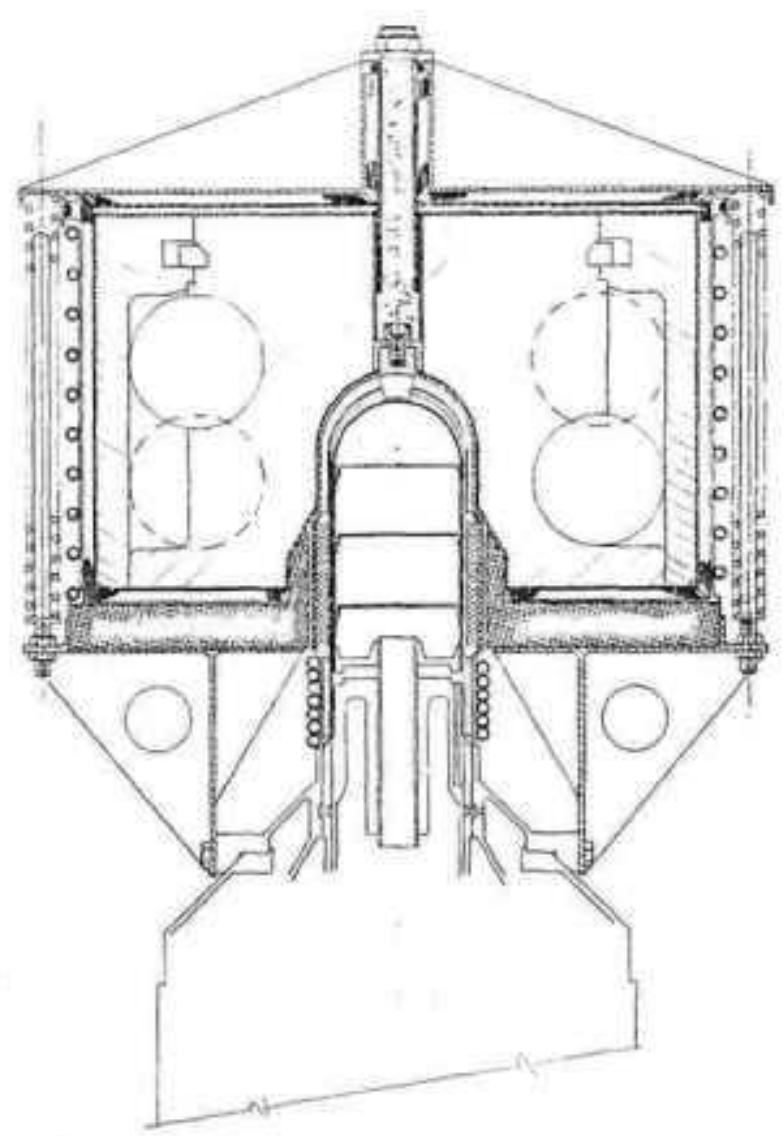

Figure 3. Ititebrative Heat sourae tieaign fon Stixling-Cycie power Syatem. 